OPEN ACCESS

Check for updates

\title{
Preterm delivery and long term mortality in women: national cohort and co-sibling study
}

\author{
Casey Crump, ${ }^{1}$ Jan Sundquist, ${ }^{2}$ Kristina Sundquist ${ }^{2}$
}

${ }^{1}$ Icahn School of Medicine at Mount Sinai, Departments of

Family Medicine and Community Health and of Population Health

Science and Policy, One Gustave

L Levy Place, Box 1077 ,

New York, NY 10029, USA

${ }^{2}$ Lund University, Centre for

Primary Health Care Research,

Clinical Research Centre, Skåne

University Hospital, Malmö,

Sweden

Correspondence to: C Crump

casey.crump@mssm.edu

(ORCID 0000-0002-2990-1166)

Additional material is published

online only. To view please visit

the journal online.

Cite this as: $B M / 2020 ; 370: \mathrm{m} 2533$

http://dx.doi.org/10.1136 bmj.m2533

Accepted: 10 June 2020

\section{ABSTRACT}

OBJECTIVES

To examine the long term mortality associated with preterm delivery in a large population based cohort of women, and to assess for potential confounding by shared familial factors.

DESIGN

National cohort study.

SETTING

Sweden.

\section{PARTICIPANTS}

All 2189477 women with a singleton delivery in 1973-2015.

\section{MAIN OUTCOME MEASURES}

All cause and cause specific mortality up to 2016, identified from nationwide death records. Cox regression was used to calculate hazard ratios while adjusting for confounders, and co-sibling analyses assessed the potential influence of unmeasured shared familial (genetic and environmental) factors.

RESULTS

In 50.7 million person years of follow-up, 76535

(3.5\%) women died (median age at death was 57.6). In the 10 years after delivery, the adjusted hazard ratio for all cause mortality associated with preterm delivery ( $(37$ weeks) was 1.73 (95\% confidence interval 1.61 to 1.87 ), and when further stratified was 2.20 (1.63 to 2.96 ) for extremely preterm delivery (22-27 weeks), 2.28 (2.01 to 2.58) for very preterm delivery (28-33 weeks), 1.52 (1.39 to 1.67 ) for late preterm delivery (34-36 weeks), and 1.19 (1.12 to 1.27) for early term delivery (37-38 weeks) compared with full term delivery (39-41 weeks). These risks declined but remained significantly raised after longer follow-up times: for preterm versus full term births, 10-19 years after delivery, the adjusted hazard ratio was 1.45 (95\% confidence interval 1.37 to 1.53 ); 20-44 years after delivery, the adjusted hazard ratio was 1.37 (1.33 to 1.41). These findings did not seem

\section{WHAT IS ALREADY KNOWN ON THIS TOPIC}

Nearly $11 \%$ of all deliveries worldwide occur preterm (gestational age $<37$ weeks) Women who deliver preterm have been reported to have increased future risks of developing heart disease and other cardiometabolic disorders, but little is known about their long term mortality risks

\section{WHAT THIS STUDY ADDS}

In a large national cohort, preterm and early term delivery were independent risk factors for premature mortality in women up to 40 years later

These findings were not explained by shared genetic or early life environmental factors in families

Women who deliver prematurely need long term clinical follow-up for detection and treatment of chronic disorders associated with early mortality to be attributable to shared genetic or environmental factors within families. Several causes were identified, including cardiovascular and respiratory disorders, diabetes, and cancer.

\section{CONCLUSIONS}

In this large national cohort of women, the findings suggested that preterm and early term delivery were independent risk factors for premature mortality from several major causes. These associations declined over time but remained raised up to 40 years later.

\section{Introduction}

Nearly $11 \%$ of all births worldwide occur preterm (gestational age <37 weeks). ${ }^{1}$ Preterm birth has been associated with long term health risks, not only in the offspring but also in mothers. Women who deliver preterm have been reported to have increased future risks of developing cardiometabolic disorders, even after controlling for other risk factors. ${ }^{2-4}$ Little is known about the long term mortality risks and underlying causes of death in these women, however. A better understanding of these outcomes is needed to identify women at high risk and guide their long term clinical care.

Previous studies have suggested that women who deliver an infant with low birth weight have higher subsequent all cause,,$^{5-7}$ cardiovascular, ${ }^{7-13}$ and diabetes related $^{14}$ mortality, after controlling for other maternal factors. But the birth weight of infants reflects the length of the pregnancy and the fetal growth rate, which are determined by different underlying processes. Mortality risks associated specifically with preterm delivery have rarely been explored and the results are conflicting, ${ }^{8-10}$ possibly because of insufficient sample sizes and follow-up time. A Swedish study of 573437 women reported that preterm delivery in 1973-80 was associated with a $23 \%$ (95\% confidence interval 14\% to 34\%) increased mortality up to 1997 , but did not examine narrower pregnancy lengths or potential confounding by other maternal factors. ${ }^{10}$ Furthermore, if such associations exist, whether they are a result of shared familial (genetic and environmental) factors that contribute to preterm delivery and early mortality, or more directly related to preterm delivery, is unclear.

To look at these knowledge gaps, we conducted a national cohort study of more than two million women in Sweden. Our goals were: to determine mortality risks associated with preterm delivery in a large population based cohort of women; to examine changes in these risks over time, with up to 44 years of follow-up; and to explore the potential influence of shared genetic or environmental factors within families by co-sibling analyses. We hypothesised that preterm delivery is 
associated with increased long term mortality and that this association might be independent of shared familial factors.

\section{Methods}

\section{Study population}

The Swedish Medical Birth Register has prenatal and birth information for nearly all deliveries in Sweden since 1973, collected by the National Board of Health and Welfare. ${ }^{15}$ From this register, we identified 2194939 women who had a singleton delivery in 19732015. Singleton deliveries were selected to improve internal comparability, given the higher prevalence of preterm delivery and its different underlying causes in multiple gestation pregnancies. ${ }^{16}$ We excluded 5462 $(0.2 \%)$ women who had missing information for length of pregnancy, leaving 2189477 women $(99.8 \%$ of the original cohort) for inclusion in the study. The study was approved by the Regional Ethical Review Board, Lund, Sweden (No 2013/736). Participant consent was not required because the study used de-identified registry based secondary data.

\section{Assessing length of pregnancy}

The length of the pregnancy was identified from the Swedish Medical Birth Register based on the maternal report of the last menstrual period in the 1970s and by ultrasonography starting in the 1980s and onwards ( $>70 \%$ of the cohort). Length of pregnancy was examined alternatively as a continuous variable or categorical variable with six groups: extremely preterm (22-27 weeks), very preterm (28-33 weeks), late preterm (34-36 weeks), early term (37-38 weeks), full term (39-41 weeks, used as the reference group), and post-term ( $\geq 42$ weeks). Also, the first three groups were combined to provide summary estimates for preterm delivery (<37 weeks).

\section{Determining mortality}

The study cohort was followed up for mortality from first delivery to 31 December 2016 (maximum followup time was 44 years; median 23.4 years). Mortality was identified from the Swedish Death Register, which includes all deaths and causes of death for all people registered in Sweden since 1960, with compulsory reporting nationwide. Cause specific mortality was examined for categories that had sufficient numbers for detailed analysis (>500 total deaths), which included cardiovascular disease (international classification of diseases, eighth and ninth revisions (ICD-8/9) codes 393-459, international classification of diseases, 10th revision (ICD-10) codes I00-I99), any cancer (ICD-8/9 codes 140-209, ICD-10 codes C00-C99), breast cancer (ICD-8/9 code 174 , ICD-10 code C50), respiratory disorders (ICD-8/9 codes 460-519, ICD-10 codes J00-J99), and diabetes mellitus (ICD-8/9 code 250, ICD-10 codes E10-E14).

\section{Other study variables}

Maternal characteristics that might be associated with preterm delivery and mortality were identified by the
Swedish Medical Birth Register and national census data, which were linked by an anonymous personal identification number and updated for each pregnancy. Maternal age was adjusted for in all analyses as the Cox model time scale (described below). Covariates included calendar year of delivery (continuous variable and categorical variable by decade), parity (1, 2, 3, 4, $\geq 5)$, highest educational level attained $(\leq 9,10-12,>12$ years), employment status (yes or no), and income (four equal groups) in the year before delivery, country or region of birth (Sweden; other Europe, United States, and Canada; Asia and Oceania; Africa; Latin America; other/unknown), body mass index (continuous and categorical <18.5, 18.5-24.9, 25.0-26.9, 27.0-29.9, $\geq 30.0$ ), and smoking (0,1-9, $\geq 10$ cigarettes/day) at the beginning of prenatal care, and pre-eclampsia (ICD-8 code 637; ICD-9 codes 624.4-624.7; ICD-10 codes 014-015), other hypertensive disorders (ICD-8 codes 400-404; ICD-9 codes 401-405, 642.0-642.3, and 642.9; ICD-10 codes I10-I15, O10-011, 013, and 015-016), diabetes mellitus (that is, pregestational type 1 or type 2, or gestational diabetes, ICD-8 code 250; ICD-9 codes 250, 648.0, and 648.8; ICD-10 codes E10-E14 and 024), asthma (ICD-8/9 code 493; ICD10 codes J45-J46), rheumatoid arthritis (ICD-8 code 712; ICD-9 code 714; ICD-10 codes M05-M06), and depression (ICD-8 code 300.4; ICD-9 code 311; ICD-10 codes F30-F39) before delivery.

Maternal body mass index and smoking were assessed at the beginning of prenatal care starting in 1982, and were available for $56.2 \%$ and $67.3 \%$ of women, respectively. Data were more than $99 \%$ complete for all other variables. Missing data for maternal body mass index or smoking were multiply imputed with linear regression and ordinal logistic regression, respectively, to produce 20 imputations, with all other covariates and mortality as predictors. ${ }^{17} 18$ As alternatives to multiple imputation, sensitivity analyses were performed that were restricted to women with complete data ( $\mathrm{n}=1201932 ; 54.9 \%)$ or coded missing data for each variable with a missing data indicator.

\section{Statistical analysis}

Cox proportional hazards regression was used to calculate hazard ratios and 95\% confidence intervals for associations between length of pregnancy and subsequent all cause or cause specific mortality. These associations were examined across the maximum possible follow-up time (up to 44 years) and in narrower time intervals of follow-up $(<10,10-19$, and 20-44 years) in women who were still alive and living in Sweden at the beginning of the respective interval. Length of pregnancy was modelled as a time dependent variable with the exposure category determined by the shortest pregnancy so far. For example, if a woman's first delivery was full term and her second was preterm, she entered the preterm exposure category at the date of her second delivery. Attained age was used as the Cox model time axis, with age at delivery as time zero. Women were censored at emigration, determined by 
the absence of a Swedish residential address in the census data $(n=93098 ; 4.3 \%)$. Emigrants and nonemigrants had similar pregnancy lengths (median 40 weeks and one day for both groups), making it unlikely that emigration introduced substantial bias. Analyses were conducted unadjusted and adjusted for covariates (that is, a confounder adjusted analysis). The proportional hazards assumption was assessed by examining log-log plots, ${ }^{19}$ and no substantial departures were found. Also, a sensitivity analysis was performed that was restricted to each woman's first delivery instead of time dependent modelling of her shortest pregnancy.

Discordant co-sibling analyses were performed to assess for potential confounding effects of unmeasured shared familial (genetic and early life environmental) factors in all 1188730 (54.3\%) women with at least one sister who had a singleton delivery. ${ }^{20}$ Shared environmental factors in families might include lifestyle factors, such as diet and physical activity, or ambient exposures, such as passive smoking or air pollution. These analyses used stratified Cox regression with a separate group for each set of sisters identified by their mother's anonymous identification number. In the stratified Cox model, each set of sisters had its own baseline hazard function that reflected their shared genetic and environmental factors, and thus associations between length of pregnancy and mortality were examined within the family, controlling for their shared factors. Also, these analyses were further adjusted for the same covariates as in the primary analyses.

Several other secondary analyses were performed. Firstly, associations between the number of preterm deliveries $(0,1, \geq 2)$ and subsequent mortality were examined in women with at least two singleton deliveries $(n=1458070)$. Secondly, mortality risks were assessed after stratifying by spontaneous $(68.5 \%)$ or medically indicated $(31.5 \%)$ preterm delivery, which was systematically recorded starting in 1990 ( $n=1218954$; maximum 27 years of followup). Thirdly, interactions were explored between length of pregnancy and pre-eclampsia or fetal growth restriction (major causes of medically indicated preterm delivery) in relation to mortality on additive and multiplicative scales. ${ }^{21}$ In these analyses, preeclampsia was identified with the same ICD codes noted above, and fetal growth restriction was assessed as small for gestational age (birth weight $<10$ th centile for gestational age) compared with appropriate for gestational age (10th-90th centiles). Fourthly, we performed subanalyses that were stratified by maternal age $(<35 v \geq 35)$ or calendar year $(<1980 v \geq 1980)$ at first delivery. All statistical tests were two sided and used an $\alpha$ level of 0.05. All analyses were conducted with Stata version 15.1.

\section{Patient and public involvement}

No patients were involved in setting the research question or outcome measures, nor were they involved in other areas of the study design or implementation because of data protection restrictions and the technical methods required to perform a data linkage analysis. The results will be disseminated to patients and the public through a website and press releases suitable for a non-specialised audience.

\section{Results}

Table 1 reports maternal characteristics by length of pregnancy. Women who delivered preterm were more likely than those who delivered full term to be younger, have fewer years of education, be unemployed, have a high body mass index, smoke 10 or more cigarettes a day, or have pre-eclampsia, other hypertensive disorders, diabetes, asthma, rheumatoid arthritis, and depression.

Median age at first delivery was 27.0 (mean 27.2, standard deviation 5.2) and $50.4(50.6,13.4)$ at the end of follow-up. In 50.7 million person years of follow-up, 76535(3.5\%) women died (median age at death was 57.6; mean 56.3, standard deviation 12.2). Table 2 reports absolute mortality rates by length of pregnancy and follow-up time.

\section{Length of pregnancy and all cause mortality}

Across the total follow-up time (0-44 years after first delivery), each additional week of pregnancy was associated with a $4 \%$ lower risk of death (full model: adjusted hazard ratio 0.96 , 95\% confidence interval 0.95 to 0.96; $\mathrm{P}<0.001$ ) (table 2). Compared with full term delivery, the adjusted hazard ratios for mortality associated with preterm, extremely preterm, or early term delivery were 1.41 (95\% confidence interval 1.38 to 1.45 ), 1.70 (1.54 to 1.89 ), and 1.11 (1.09 to 1.13 ), respectively. These fully adjusted hazard ratios were only modestly lower than those adjusted only for age (table 2).

During the first 10 years after delivery, the adjusted hazard ratio for mortality associated with preterm delivery was 1.73 (95\% confidence interval 1.61 to 1.87), and when further stratified was 2.20 (1.63 to 2.96) for extremely preterm delivery, 2.28 (2.01 to 2.58) for very preterm delivery, 1.52 (1.39 to 1.67) for late preterm delivery, and 1.19 (1.12 to 1.27) for early term delivery, compared with full term delivery (table 2). After longer follow-up times (10-19 and 20-44 years after delivery), the association between preterm delivery and mortality declined but remained significantly raised (eg, full model: adjusted hazard ratio 10-19 years after delivery was 1.45, 95\% confidence interval 1.37 to $1.53, \mathrm{P}<0.001$; adjusted hazard ratio 20-44 years after delivery was 1.37, 1.33 to $1.41, \mathrm{P}<0.001)$. Early term delivery was associated with a slightly increased risk of mortality, even 20-44 years later, compared with full term delivery (adjusted hazard ratio $1.10,1.08$ to $1.13, \mathrm{P}<0.001$ ).

Whereas hazard ratios were highest in the first 10 years after delivery and then declined, absolute mortality differences associated with preterm delivery increased with longer follow-up times (fig 1). Preterm delivery accounted for 28.3 (95\% confidence interval 23.8 to 32.8 ) excess deaths per 100000 person years 


\begin{tabular}{|c|c|c|c|c|c|c|}
\hline & $\begin{array}{l}\text { Extremely } \\
\text { preterm (22-27 } \\
\text { weeks; } n=9107)\end{array}$ & $\begin{array}{l}\text { Very preterm } \\
\text { (28-33 weeks; } \\
n=45453)\end{array}$ & $\begin{array}{l}\text { Late preterm } \\
(34-36 \text { weeks; } \\
n=140262)\end{array}$ & $\begin{array}{l}\text { Early term } \\
(37-38 \text { weeks; } \\
n=551 \text { 854) }\end{array}$ & $\begin{array}{l}\text { Full term } \\
\text { (39-41 weeks; } \\
n=1353288)\end{array}$ & $\begin{array}{l}\text { Post-term } \\
(\geq 42 \text { weeks; } \\
n=89513)\end{array}$ \\
\hline \multicolumn{7}{|c|}{ Age at first delivery (years) } \\
\hline$<20$ & $806(8.9)$ & $4125(9.1)$ & $11408(8.1)$ & $35953(6.5)$ & $64179(4.7)$ & $2810(3.1)$ \\
\hline $20-24$ & $2586(28.4)$ & $13335(29.3)$ & $42393(30.2)$ & $162343(29.4)$ & $364050(26.9)$ & $17756(19.8)$ \\
\hline $25-29$ & $2776(30.5)$ & $14590(32.1)$ & $47287(33.7)$ & $194633(35.3)$ & $498643(36.9)$ & $31062(34.7)$ \\
\hline $30-34$ & $1875(20.6)$ & 9050 (19.9) & 27469 (19.6) & $112857(20.4)$ & $304799(22.5)$ & $24744(27.6)$ \\
\hline $35-39$ & $856(9.4)$ & $3502(7.7)$ & $9659(6.9)$ & $37810(6.9)$ & $101802(7.5)$ & $11045(12.3)$ \\
\hline$\geq 40$ & $208(2.3)$ & 851 (1.9) & $2046(1.5)$ & $8258(1.5)$ & $19815(1.5)$ & $2096(2.3)$ \\
\hline \multicolumn{7}{|l|}{ Year of delivery } \\
\hline 1973-79 & 1445 (15.9) & $10135(22.3)$ & $31075(22.2)$ & $112458(20.4)$ & $338112(25.0)$ & 33917 (37.9) \\
\hline 1980-89 & $1773(19.5)$ & $10762(23.7)$ & $33789(24.1)$ & $126390(22.9)$ & 258787 (19.1) & $11880(13.3)$ \\
\hline 1990-99 & $1992(21.9)$ & $10008(22.0)$ & $30445(21.7)$ & $121720(22.1)$ & $267628(19.8)$ & 12207 (13.6) \\
\hline 2000-09 & $2244(24.6)$ & $9334(20.5)$ & $29165(20.8)$ & $126519(22.9)$ & $279267(20.6)$ & $12950(14.5)$ \\
\hline 2010-15 & $1653(18.1)$ & $5214(11.5)$ & $15788(11.3)$ & $64767(11.7)$ & $209494(15.5)$ & $18559(20.7)$ \\
\hline \multicolumn{7}{|l|}{ Final parity } \\
\hline 1 & $1726(19.0)$ & $8351(18.4)$ & $23570(16.8)$ & $86312(15.6)$ & $326645(24.1)$ & $46393(51.8)$ \\
\hline 2 & $3074(33.7)$ & $18081(39.8)$ & $62541(44.6)$ & $263495(47.8)$ & $669721(49.5)$ & $29682(33.2)$ \\
\hline 3 & $2500(27.5)$ & $11462(25.2)$ & $34768(24.8)$ & $140378(25.4)$ & $269132(19.9)$ & $9981(11.2)$ \\
\hline 4 & $1128(12.4)$ & $4746(10.4)$ & $12665(9.0)$ & $42744(7.7)$ & $64302(4.8)$ & $2432(2.7)$ \\
\hline$\geq 5$ & $678(7.4)$ & $2813(6.2)$ & $6718(4.8)$ & $18925(3.4)$ & $23488(1.7)$ & $1025(1.1)$ \\
\hline \multicolumn{7}{|c|}{ Education (No of years) } \\
\hline$<10$ & $1509(16.6)$ & $7498(16.5)$ & $21411(15.3)$ & $75848(13.7)$ & $181808(13.4)$ & $16089(18.0)$ \\
\hline $10-12$ & $4218(46.3)$ & $21524(47.4)$ & $65466(46.7)$ & 247739 (44.9) & $591395(43.7)$ & $38777(43.3)$ \\
\hline$>12$ & $3380(37.1)$ & $16431(36.1)$ & $53385(38.1)$ & $228267(41.4)$ & $580085(42.9)$ & $34647(38.7)$ \\
\hline Employment & $7530(82.7)$ & $38293(84.3)$ & $120085(85.6)$ & $474869(86.0)$ & $1173768(86.7)$ & $75520(84.4)$ \\
\hline \multicolumn{7}{|l|}{ Income (group) } \\
\hline 1st (highest) & $2500(27.4)$ & $10395(22.9)$ & $31264(22.3)$ & $131193(23.8)$ & $348942(25.8)$ & $24446(27.3)$ \\
\hline 2nd & $2225(24.4)$ & $10730(23.6)$ & 33581 (23.9) & $132327(24.0)$ & $342045(25.3)$ & $25358(28.3)$ \\
\hline $3 r d$ & $1912(21.0)$ & $11606(25.5)$ & $35905(25.6)$ & $138566(25.1)$ & $339010(25.0)$ & $22456(25.1)$ \\
\hline 4th (lowest) & $2470(27.1)$ & $12722(28.0)$ & $39512(28.2)$ & $149768(27.1)$ & $323291(23.9)$ & $17253(19.3)$ \\
\hline \multicolumn{7}{|l|}{ Birth country or region } \\
\hline Sweden & $6958(76.4)$ & $37443(82.4)$ & $116310(82.9)$ & $449542(81.5)$ & $1114652(82.4)$ & $72312(80.8)$ \\
\hline $\begin{array}{l}\text { Other Europe, US, } \\
\text { and Canada }\end{array}$ & $964(10.6)$ & $3976(8.8)$ & $12130(8.7)$ & 48858 (8.9) & $128986(9.5)$ & $10410(11.6)$ \\
\hline Asia and Oceania & 741 (8.1) & $2673(5.9)$ & $8359(6.0)$ & $38262(6.9)$ & $73897(5.5)$ & $3702(4.1)$ \\
\hline Africa & $327(3.6)$ & $902(2.0)$ & $1933(1.4)$ & $8164(1.5)$ & $21728(1.6)$ & $2210(2.5)$ \\
\hline Latin America & $108(1.2)$ & $399(0.9)$ & $1391(1.0)$ & $6486(1.2)$ & $12656(0.9)$ & $759(0.9)$ \\
\hline Other and unknown & $9(0.1)$ & $60(0.1)$ & $139(1.0)$ & $542(0.1)$ & $1369(0.1)$ & $120(0.1)$ \\
\hline \multicolumn{7}{|l|}{ Body mass index } \\
\hline$<18.5$ & $223(2.4)$ & $1294(2.9)$ & $4215(3.0)$ & $16243(2.9)$ & $29739(2.2)$ & $1048(1.2)$ \\
\hline $18.5-24.9$ & $6927(76.1)$ & $36701(80.7)$ & $114059(81.3)$ & $450513(81.6)$ & $1110089(82.0)$ & 72124 (80.6) \\
\hline $25.0-26.9$ & $826(9.1)$ & $2994(6.6)$ & $8986(6.4)$ & $36556(6.6)$ & $93683(6.9)$ & $6349(7.1)$ \\
\hline $27.0-29.9$ & $524(5.7)$ & $2182(4.8)$ & 6689 (4.8) & $25993(4.7)$ & $64608(4.8)$ & $4864(5.4)$ \\
\hline$\geq 30.0$ & $607(6.7)$ & $2282(5.0)$ & $6313(4.5)$ & $22549(4.1)$ & $55169(4.1)$ & $5128(5.7)$ \\
\hline \multicolumn{7}{|l|}{ Smoking (cigarettes/day) } \\
\hline 0 & $6603(72.5)$ & $31253(68.8)$ & 99901 (71.2) & $410401(74.4)$ & $992980(73.4)$ & $57915(64.7)$ \\
\hline $1-9$ & $2061(22.6)$ & $12038(26.5)$ & $34535(24.6)$ & $121547(22.0)$ & $321942(23.8)$ & $29569(33.0)$ \\
\hline$\geq 10$ & $443(4.9)$ & $2162(4.8)$ & $5826(4.2)$ & $19906(3.6)$ & $38366(2.8)$ & $2029(2.3)$ \\
\hline Pre-eclampsia & 1030 (11.3) & 6999 (15.4) & $14165(10.1)$ & $35705(6.5)$ & $61312(4.5)$ & $4101(4.6)$ \\
\hline $\begin{array}{l}\text { Other hypertensive } \\
\text { disorders }\end{array}$ & $102(1.1)$ & $681(1.5)$ & $1758(1.3)$ & 6234 (1.1) & $12615(0.9)$ & $738(0.8)$ \\
\hline Diabetes mellitus & $214(2.4)$ & $1390(3.1)$ & $4323(3.1)$ & 9995 (1.8) & $11098(0.8)$ & $477(0.5)$ \\
\hline Asthma & $324(3.6)$ & $1447(3.2)$ & $4191(3.0)$ & $15344(2.8)$ & $32089(2.4)$ & $1990(2.2)$ \\
\hline Rheumatoid arthritis & $60(0.7)$ & $322(0.7)$ & $966(0.7)$ & $3267(0.6)$ & $6302(0.5)$ & $406(0.5)$ \\
\hline Depression & $619(6.8)$ & $2501(5.5)$ & $7411(5.3)$ & $27163(4.9)$ & $54434(5.0)$ & $3663(4.1)$ \\
\hline
\end{tabular}

at less than 10 years after delivery, 48.0 (40.1 to 55.7) excess deaths at 10-19 years after delivery, and 143.4 (128.7 to 158.3) excess deaths at 20-44 years after delivery, compared with full term delivery (table 2, risk differences). At less than 10, 10-19, and 20-44 years of follow-up, respectively, an estimated $48.0 \%$, $38.0 \%$, and $30.1 \%$ of deaths in women who delivered preterm, and $8.7 \%, 5.8 \%$, and $3.3 \%$ of all deaths in the population, were related to preterm delivery (table
2, attributable fraction and population attributable fraction). An estimated 2654 excess deaths in this population were associated with preterm delivery (one excess death per 73 women who delivered preterm). Kaplan-Meier survival curves by length of pregnancy are shown in supplementary figure 1.

In sensitivity analyses that were restricted to women with complete data or that coded missing data with a missing data indicator, all results were similar to 


\begin{tabular}{|c|c|c|c|c|c|c|c|c|}
\hline & \multirow[b]{2}{*}{ Deaths } & \multirow[b]{2}{*}{ Rate* } & \multirow{2}{*}{$\begin{array}{l}\text { Reduced model } \\
\text { (hazard ratio, } 95 \% \mathrm{Cl}) \dagger\end{array}$} & \multicolumn{2}{|l|}{ Full model‡ } & \multirow[b]{2}{*}{ Risk difference $(95 \% \mathrm{Cl}) \S$} & \multirow[b]{2}{*}{$\operatorname{AF}(\%)$} & \multirow[b]{2}{*}{ PAF (\%) } \\
\hline & & & & Hazard ratio $(95 \% \mathrm{Cl})$ & $P$ value & & & \\
\hline \multicolumn{9}{|l|}{$0-44$ years after delivery } \\
\hline Preterm (<37 weeks) & 8618 & 206.5 & $1.50(1.47$ to 1.54$)$ & 1.41 (1.38 to 1.45$)$ & $<0.001$ & $63.6(58.2$ to 69.0$)$ & 30.8 & 4.8 \\
\hline Extremely preterm (22-27 weeks) & 378 & 227.0 & $1.82(1.64$ to 2.01$)$ & $1.70(1.54$ to 1.89$)$ & $<0.001$ & 84.1 (54.9 to 113.3$)$ & 37.8 & 0.3 \\
\hline Very preterm (28-33 weeks) & 2315 & 234.2 & $1.72(1.65$ to 1.80$)$ & 1.61 (1.54 to 1.68$)$ & $<0.001$ & $91.3(79.5$ to 103.1$)$ & 39.4 & 1.9 \\
\hline Late preterm (34-36 weeks) & 5925 & 196.9 & $1.42(1.38$ to 1.45$)$ & $1.34(1.30$ to 1.37$)$ & $<0.001$ & $54.0(47.9$ to 60.2$)$ & 27.4 & 3.0 \\
\hline Early term (37-38 weeks) & 17671 & 162.4 & $1.16(1.13$ to 1.18$)$ & 1.11 (1.09 to 1.13$)$ & $<0.001$ & 19.5 (16.4 to 22.6$)$ & 12.0 & 3.2 \\
\hline Full term (39-41 weeks) & 45338 & 142.9 & Reference & Reference & - & Reference & - & - \\
\hline Post-term ( $\geq 42$ weeks) & 4908 & 158.9 & 1.05 (1.03 to 1.08$)$ & 1.03 (1.00 to 1.07) & 0.02 & $16.0(12.4$ to 19.6$)$ & 10.1 & 1.5 \\
\hline Per additional week (trend) & - & - & $0.96(0.95$ to 0.96$)$ & $0.96(0.95$ to 0.96$)$ & $<0.001$ & - & - & - \\
\hline \multicolumn{9}{|l|}{$<10$ years after delivery } \\
\hline Preterm ( $<37$ weeks) & 849 & 58.4 & 1.85 (1.72 to 1.99$)$ & $1.73(1.61$ to 1.87$)$ & $<0.001$ & 28.3 (23.8 to 32.8$)$ & 48.0 & 8.7 \\
\hline Extremely preterm (22-27 weeks) & 44 & 71.8 & 2.18 (1.62 to 2.93$)$ & 2.20 (1.63 to 2.96$)$ & $<0.001$ & 41.7 (20.4 to 62.9) & 58.0 & 0.7 \\
\hline Very preterm (28-33 weeks) & 269 & 80.0 & $2.50(2.21$ to 2.83$)$ & 2.28 (2.01 to 2.58$)$ & $<0.001$ & $49.9(40.3$ to 59.5$)$ & 62.3 & 4.1 \\
\hline Late preterm (34-36 weeks) & 536 & 50.2 & 1.62 (1.48 to 1.77$)$ & $1.52(1.39$ to 1.67$)$ & $<0.001$ & 20.1 (15.8 to 24.5$)$ & 41.3 & 4.9 \\
\hline Early term (37-38 weeks) & 1532 & 38.7 & $1.23(1.15$ to 1.31$)$ & $1.19(1.12$ to 1.27$)$ & $<0.001$ & $8.6(6.2$ to 11.0$)$ & 21.9 & 5.2 \\
\hline Full term (39-41 weeks) & 3832 & 30.1 & Reference & Reference & - & Reference & - & - \\
\hline Post-term ( $\geq 42$ weeks) & 437 & 32.1 & $1.06(0.98$ to 1.16$)$ & 0.99 (0.90 to 1.10$)$ & 0.92 & $2.0(-0.8$ to 4.7$)$ & 6.0 & 0.8 \\
\hline Per additional week (trend) & - & - & 0.93 (0.92 to 0.94) & 0.93 (0.92 to 0.94) & $<0.001$ & - & - & - \\
\hline \multicolumn{9}{|l|}{ 10-19 years after delivery } \\
\hline Preterm ( $<37$ weeks) & 1536 & 126.3 & $1.52(1.44$ to 1.61$)$ & $1.45(1.37$ to 1.53$)$ & $<0.001$ & $48.0(40.1$ to 55.7$)$ & 38.0 & 5.8 \\
\hline Extremely preterm (22-27 weeks) & 62 & 123.7 & 1.53 (1.19 to 1.96$)$ & $1.49(1.16$ to 1.91$)$ & 0.002 & $45.4(15.5$ to 75.3$)$ & 36.7 & 0.3 \\
\hline Very preterm (28-33 weeks) & 416 & 147.9 & 1.74 (1.57 to 1.92$)$ & $1.63(1.47$ to 1.80$)$ & $<0.001$ & $69.6(52.3$ to 86.9$)$ & 47.1 & 2.3 \\
\hline Late preterm (34-36 weeks) & 1058 & 119.7 & 1.45 (1.36 to 1.55$)$ & 1.39 (1.30 to 1.48$)$ & $<0.001$ & $41.4(32.6$ to 50.1$)$ & 34.6 & 3.7 \\
\hline Early term (37-38 weeks) & 3015 & 96.2 & $1.17(1.12$ to 1.23$)$ & 1.10 (1.06 to 1.15$)$ & $<0.001$ & 17.9 (13.5 to 22.2) & 18.6 & 4.2 \\
\hline Full term (39-41 weeks) & 7026 & 78.3 & Reference & Reference & - & Reference & - & - \\
\hline Post-term ( $\geq 42$ weeks) & 680 & 81.0 & 1.05 (0.98 to 1.11) & 1.04 (0.96 to 1.13$)$ & 0.32 & $2.7(-2.2$ to 7.5$)$ & 3.3 & 0.4 \\
\hline Per additional week (trend) & - & - & $0.96(0.95$ to 0.97$)$ & $0.96(0.95$ to 0.96$)$ & $<0.001$ & - & - & - \\
\hline \multicolumn{9}{|l|}{ 20-44 years after delivery } \\
\hline Preterm (<37 weeks) & 6233 & 476.3 & 1.45 (1.41 to 1.49$)$ & $1.37(1.33$ to 1.41$)$ & $<0.001$ & 143.4 (128.7 to 158.3$)$ & 30.1 & 3.3 \\
\hline Extremely preterm (22-27 weeks) & 272 & 600.6 & 1.84 (1.63 to 2.07$)$ & 1.68 (1.49 to 1.89$)$ & $<0.001$ & 267.7 (176.3 to 359.2$)$ & 44.6 & 0.3 \\
\hline Very preterm (28-33 weeks) & 1630 & 522.3 & 1.62 (1.54 to 1.70$)$ & 1.52 (1.44 to 1.60$)$ & $<0.001$ & 189.4 (157.6 to 221.2$)$ & 36.3 & 1.3 \\
\hline Late preterm (34-36 weeks) & 4331 & 457.0 & 1.37 (1.33 to 1.42$)$ & 1.30 (1.26 to 1.35$)$ & $<0.001$ & $124.1(107.4$ to 140.9$)$ & 27.2 & 2.0 \\
\hline Early term (37-38 weeks) & 13124 & 387.1 & 1.14 (1.12 to 1.17$)$ & 1.10 (1.08 to 1.13$)$ & $<0.001$ & $54.2(45.8$ to 62.8$)$ & 14.0 & 2.9 \\
\hline Full term (39-41 weeks) & 34480 & 332.9 & Reference & Reference & - & Reference & - & - \\
\hline Post-term ( $\geq 42$ weeks) & 3791 & 344.0 & 1.05 (1.02 to 1.08$)$ & $1.04(1.00$ to 1.07$)$ & 0.03 & $11.1(2.2$ to 20.0$)$ & 3.2 & 0.5 \\
\hline Per additional week (trend) & - & - & $0.96(0.96$ to 0.96$)$ & $0.96(0.96$ to 0.96$)$ & $<0.001$ & - & - & - \\
\hline \multicolumn{9}{|c|}{$\begin{array}{l}\text { AF=attributable fraction in the respective pregnancy length group. } \mathrm{PAF}=\text { population attributable fraction. } \\
{ }^{*} \text { Mortality rate per } 100000 \text { person years. } \\
\text { †Adjusted for maternal age as the Cox model time scale. }\end{array}$} \\
\hline
\end{tabular}

the main results, and the overall conclusions were unchanged (eg, fully adjusted hazard ratios for mortality after 0-44 years of follow-up for preterm compared with full term were 1.34 (95\% confidence interval 1.28 to 1.40 ), $\mathrm{P}<0.001$ and 1.40 (1.37 to 1.43 ), $\mathrm{P}<0.001$, respectively). In the complete case analysis, adjustment for maternal body mass index and smoking had only a modest effect on risk estimates (that is, they were not major confounders). Also, the corresponding adjusted hazard ratio when considering each woman's first delivery, instead of her shortest pregnancy adjusted for parity, was 1.42 (95\% confidence interval 1.38 to $1.46, \mathrm{P}<0.001)$.

\section{Co-sibling analyses}

Co-sibling analyses to control for unmeasured shared familial factors showed little change in risk estimates (table 3). For example, comparing preterm with full term delivery, the adjusted hazard ratios for mortality at less than 10 years after delivery were 1.73 (95\% confidence interval 1.61 to 1.87 ) in the primary analysis versus 1.68 (1.20 to 2.35$)$ in the co-sibling analysis; at 10-19 years after delivery, 1.45 (1.37 to 1.53) versus 1.46 (1.19 to 1.80$)$; and at 20-44 years after delivery, 1.37 (1.33 to 1.41 ) versus 1.37 (1.27 to 1.49). These findings suggested that the associations seen in the primary analyses were not attributable to shared genetic or early life environmental factors in families.

\section{Length of pregnancy and cause specific mortality} Associations between length of pregnancy and cause specific mortality are reported in table 4. In the whole cohort, $10753(14.0 \%)$ deaths were from cardiovascular disease, 37371 (48.8\%) from cancer (including 8447 (11.0\%) from breast cancer), 2704 (3.5\%) from respiratory disorders, 900 (1.2\%) from diabetes, and 24807 (32.4\%) from other causes. Comparing preterm with full term delivery, the adjusted hazard ratio for cardiovascular mortality across the whole follow-up time (0-44 years) was 1.79 (95\% confidence interval 1.69 to $1.90, \mathrm{P}<0.001$ ), for 


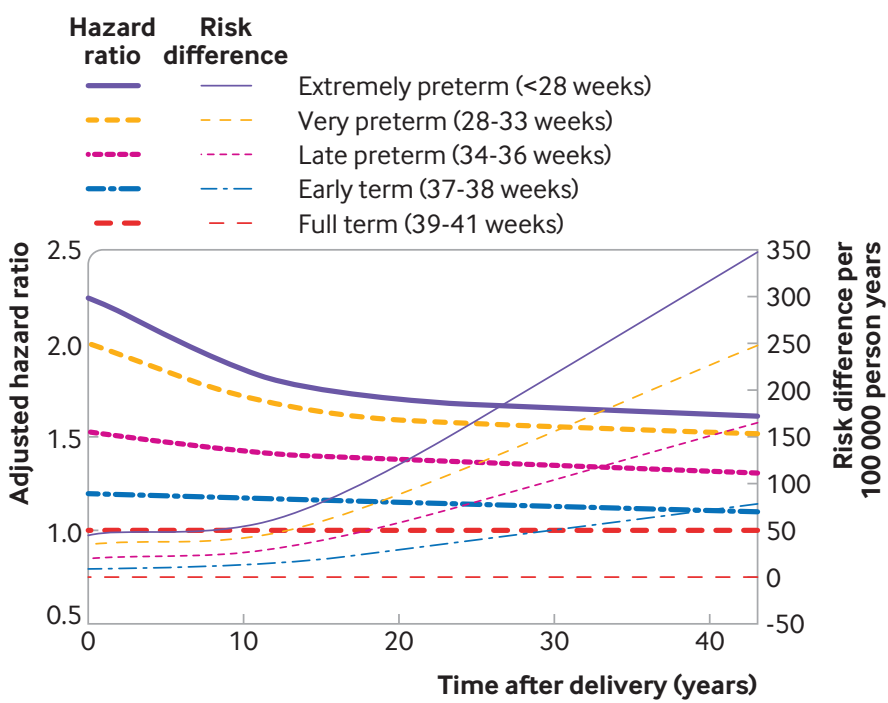

Fig 1 | Hazard ratios and absolute risk differences for all cause mortality in women by length of pregnancy compared with full term, Sweden, 1973-2016

any cancer mortality was 1.18 (1.14 to $1.23, \mathrm{P}<0.001)$, for breast cancer mortality was 1.11 (1.03 to 1.20 , $\mathrm{P}=0.009)$, for respiratory mortality was 2.15 (1.92 to 2.40, $\mathrm{P}<0.001)$, for diabetes mortality was 3.20 (2.69 to 3.82, $\mathrm{P}<0.001)$, and for all other causes combined was 1.53 (1.47 to $1.59, \mathrm{P}<0.001)$. Each of these outcomes had a gradient of higher risks by shorter length of pregnancy (table 4).

\section{Secondary analyses}

Table 5 reports the associations between the number of preterm deliveries and mortality. Women with more than one preterm delivery had further increases in mortality risk. In women with at least two singleton deliveries, the adjusted hazard ratios for mortality

\begin{tabular}{|c|c|c|c|}
\hline & Deaths & Hazard ratio $(95 \% \mathrm{CI})^{\star}$ & $P$ value \\
\hline \multicolumn{4}{|l|}{$0-44$ years after delivery } \\
\hline Preterm (<37 weeks) & 5018 & $1.39(1.30$ to 1.48$)$ & $<0.001$ \\
\hline Early term (37-38 weeks) & 10077 & $1.10(1.05$ to 1.16$)$ & $<0.001$ \\
\hline Full term (39-41 weeks) & 19738 & Reference & - \\
\hline Per additional week (trend) & - & $0.95(0.94$ to 0.96$)$ & $<0.001$ \\
\hline \multicolumn{4}{|l|}{$<10$ years after delivery } \\
\hline Preterm $(<37$ weeks $)$ & 940 & $1.68(1.20$ to 2.35$)$ & 0.003 \\
\hline Early term (37-38 weeks) & 1694 & $1.20(0.93$ to 1.56$)$ & 0.17 \\
\hline Full-term (39-41 weeks) & 3047 & Reference & - \\
\hline Per additional week (trend) & - & $0.92(0.88$ to 0.96$)$ & $<0.001$ \\
\hline \multicolumn{4}{|l|}{$10-19$ years after delivery } \\
\hline Preterm (<37 weeks) & 1402 & $1.46(1.19$ to 1.80$)$ & $<0.001$ \\
\hline Early term (37-38 weeks) & 2812 & $1.12(0.97$ to 1.30$)$ & 0.11 \\
\hline Full term (39-41 weeks) & 4926 & Reference & - \\
\hline Per additional week (trend) & - & 0.95 (0.93 to 0.98) & 0.001 \\
\hline \multicolumn{4}{|l|}{ 20-44 years after delivery } \\
\hline Preterm (<37 weeks) & 2676 & $1.37(1.27$ to 1.49$)$ & $<0.001$ \\
\hline Early term (37-38 weeks) & 5571 & $1.08(1.02$ to 1.14$)$ & 0.01 \\
\hline Full term (39-41 weeks) & 11765 & Reference & - \\
\hline Per additional week (trend) & - & $0.96(0.95$ to 0.97$)$ & $<0.001$ \\
\hline
\end{tabular}

for each additional preterm delivery were 1.13 (95\% confidence interval 1.04 to 1.24$)$ at less than 10 years, 1.25 (1.19 to 1.31$)$ at $10-19$ years, and 1.24 (1.21 to 1.27) at 20-44 years after first delivery.

Spontaneous and medically indicated preterm delivery were associated with significantly increased mortality compared with full term delivery (adjusted hazard ratios 1.21 (95\% confidence interval 1.08 to 1.35, $\mathrm{P}=0.001$ ) and 1.70 (1.52 to $1.90, \mathrm{P}<0.001$ ), respectively), but medically indicated preterm delivery (eg, for pre-eclampsia or other complications) was the stronger risk factor $(\mathrm{P}<0.001$ for difference in hazard ratios).

Interactions between length of pregnancy and pre-eclampsia are reported in supplementary table 1. Preterm delivery was associated with increased mortality risks in the long term when pre-eclampsia was present (adjusted hazard ratio 1.59, 95\% confidence interval 1.53 to $1.65, \mathrm{P}<0.001)$ or not present $(1.51,1.45$ to $1.56, \mathrm{P}<0.001)$ (supplementary table 1). No significant interactions were found between preterm delivery and pre-eclampsia on the additive or multiplicative scale.

Preterm delivery and having an infant who was small for gestational age were independently associated with increased mortality (eg, adjusted hazard ratios: preterm $v$ full term, 1.40 (95\% confidence interval 1.36 to 1.44, $\mathrm{P}<0.001)$; small for gestational age $v$ appropriate for gestational age, 1.33 (1.30 to $1.36, \mathrm{P}<0.001)$ ), but preterm delivery was the stronger risk factor ( $\mathrm{P}=0.004$ for difference in hazard ratios). Women who delivered preterm had increased mortality regardless of whether their infant was small for gestational age (adjusted hazard ratio 1.29 (1.21 to 1.38$), \mathrm{P}<0.001$ ) or appropriate for gestational age (1.42 (1.38 to 1.46), $\mathrm{P}<0.001$; supplementary table 2 ). A negative multiplicative (but not additive) interaction was found between preterm delivery and small for gestational age (that is, their combined effect on long term mortality was less than the product of their separate effects, $\mathrm{P}=0.008)$. The absence of an additive interaction suggests that preterm delivery was associated with a similar number of deaths in women who had infants who were appropriate for gestational age versus small for gestational age. Stratified subanalyses showed that associations between length of pregnancy or number of preterm deliveries and mortality did not vary significantly by maternal age $(<35 v \geq 35)$ or calendar year $(<1980 v \geq 1980)$ at first delivery (supplementary table 3).

\section{Discussion}

In this large national cohort, length of pregnancy in women was inversely associated with their long term mortality risk, after adjusting for many other risk factors. Women who delivered preterm or extremely preterm had 1.7-fold and 2.2-fold mortality risks, respectively, during the next 10 years compared with those who delivered full term. These risks subsequently declined but remained significantly raised even 20-44 years after delivery (more than 1.3-fold and 1.6-fold, 


\begin{tabular}{|c|c|c|c|}
\hline & Deaths & Hazard ratio $(95 \% \mathrm{Cl})^{\star}$ & $P$ value \\
\hline \multicolumn{4}{|l|}{ Cardiovascular } \\
\hline Preterm ( $<37$ weeks) & 1475 & 1.79 (1.69 to 1.90$)$ & $<0.001$ \\
\hline Extremely preterm (22-27 weeks) & 62 & 2.09 (1.62 to 2.68$)$ & $<0.001$ \\
\hline Very preterm (28-33 weeks) & 446 & $2.30(2.09$ to 2.54$)$ & $<0.001$ \\
\hline Late preterm (34-36 weeks) & 967 & $1.62(1.51$ to 1.73$)$ & $<0.001$ \\
\hline Early term (37-38 weeks) & 2592 & $1.26(1.21$ to 1.32$)$ & $<0.001$ \\
\hline Full term (39-41 weeks) & 5941 & Reference & - \\
\hline Post-term ( $\geq 42$ weeks) & 745 & $1.11(1.02$ to 1.19$)$ & 0.01 \\
\hline Per additional week (trend) & - & 0.91 (0.90 to 0.92) & $<0.001$ \\
\hline \multicolumn{4}{|l|}{ Cancer } \\
\hline Preterm ( $<37$ weeks) & 3519 & $1.18(1.14$ to 1.23$)$ & $<0.001$ \\
\hline Extremely preterm (22-27 weeks) & 142 & 1.34 (1.13 to 1.58$)$ & 0.001 \\
\hline Very preterm (28-33 weeks) & 903 & $1.29(1.21$ to 1.38$)$ & $<0.001$ \\
\hline Late preterm (34-36 weeks) & 2474 & $1.14(1.10$ to 1.19$)$ & $<0.001$ \\
\hline Early term (37-38 weeks) & 8321 & $1.04(1.01$ to 1.06$)$ & 0.007 \\
\hline Full term (39-41 weeks) & 23169 & Reference & - \\
\hline Post-term ( $\geq 42$ weeks) & 2362 & $1.00(0.96$ to 1.05$)$ & 0.83 \\
\hline Per additional week (trend) & - & 0.97 (0.97 to 0.98) & $<0.001$ \\
\hline \multicolumn{4}{|l|}{ Breast cancer } \\
\hline Preterm (<37 weeks) & 752 & $1.11(1.03$ to 1.20$)$ & 0.009 \\
\hline Extremely preterm (22-27 weeks) & 35 & $1.45(1.04$ to 2.02$)$ & 0.03 \\
\hline Very preterm (28-33 weeks) & 195 & $1.23(1.06$ to 1.42$)$ & 0.005 \\
\hline Late preterm (34-36 weeks) & 522 & $1.05(0.96$ to 1.15$)$ & 0.26 \\
\hline Early term (37-38 weeks) & 1938 & 1.03 (0.98 to 1.09$)$ & 0.26 \\
\hline Full term (39-41 weeks) & 5234 & Reference & - \\
\hline Post-term ( $\geq 42$ weeks) & 523 & $1.06(0.97$ to 1.16$)$ & 0.19 \\
\hline Per additional week (trend) & - & 0.99 (0.98 to 1.00$)$ & 0.07 \\
\hline \multicolumn{4}{|l|}{ Respiratory } \\
\hline Preterm (<37 weeks) & 416 & $2.15(1.92$ to 2.40$)$ & $<0.001$ \\
\hline Extremely preterm (22-27 weeks) & 23 & $3.24(2.14$ to 4.90$)$ & $<0.001$ \\
\hline Very preterm (28-33 weeks) & 96 & 2.11 (1.71 to 2.60$)$ & $<0.001$ \\
\hline Late preterm (34-36 weeks) & 297 & 2.11 (1.86 to 2.39$)$ & $<0.001$ \\
\hline Early term (37-38 weeks) & 630 & 1.31 (1.19 to 1.44$)$ & $<0.001$ \\
\hline Full term (39-41 weeks) & 1478 & Reference & - \\
\hline Post-term ( $\geq 42$ weeks) & 180 & 0.99 (0.84 to 1.15$)$ & 0.86 \\
\hline Per additional week (trend) & - & $0.90(0.89$ to 0.91$)$ & $<0.001$ \\
\hline \multicolumn{4}{|l|}{ Diabetes } \\
\hline Preterm (<37 weeks) & 237 & 3.20 (2.69 to 3.82$)$ & $<0.001$ \\
\hline Extremely preterm (22-27 weeks) & 9 & 4.37 (2.24 to 8.53$)$ & $<0.001$ \\
\hline Very preterm (28-33 weeks) & 60 & $3.84(2.90$ to 5.07$)$ & $<0.001$ \\
\hline Late preterm (34-36 weeks) & 168 & $2.98(2.45$ to 3.61$)$ & $<0.001$ \\
\hline Early term (37-38 weeks) & 263 & $1.66(1.41$ to 1.96$)$ & $<0.001$ \\
\hline Full term (39-41 weeks) & 359 & Reference & - \\
\hline Post-term ( $\geq 42$ weeks) & 41 & $0.99(0.72$ to 1.37$)$ & 0.96 \\
\hline Per additional week (trend) & - & $0.84(0.82$ to 0.86$)$ & $<0.001$ \\
\hline \multicolumn{4}{|l|}{ Other causes } \\
\hline Preterm (<37 weeks) & 2971 & $1.53(1.47$ to 1.59$)$ & $<0.001$ \\
\hline Extremely preterm (22-27 weeks) & 142 & 1.94 (1.64 to 2.29$)$ & $<0.001$ \\
\hline Very preterm (28-33 weeks) & 810 & $1.77(1.65$ to 1.90$)$ & $<0.001$ \\
\hline Late preterm (34-36 weeks) & 2019 & $1.43(1.36$ to 1.50$)$ & $<0.001$ \\
\hline Early term (37-38 weeks) & 5865 & $1.16(1.13$ to 1.20$)$ & $<0.001$ \\
\hline Full term (39-41 weeks) & 14391 & Reference & - \\
\hline Post-term ( $\geq 42$ weeks) & 1580 & $1.04(0.99$ to 1.10$)$ & 0.13 \\
\hline Per additional week (trend) & - & $0.94(0.94$ to 0.95$)$ & $<0.001$ \\
\hline
\end{tabular}

respectively). Even early term delivery (37-38 weeks) was associated with modestly increased mortality risks that persisted 20-44 years later. Co-sibling analyses suggested that these findings were not explained by shared genetic or early life environmental factors in families. The absolute mortality risks associated with preterm delivery were overall low but increased with longer follow-up times. Several major causes of death were identified, including cardiovascular and respiratory disorders, diabetes, and cancer.

\section{Strengths and limitations of the study}

A key strength of the study was the large national cohort design with up to 44 years of follow-up. The availability of highly complete birth, death, and covariate data from national registries helped minimise potential selection and ascertainment biases. The large sample size enabled high statistical power needed to examine narrowly defined pregnancy durations. The results were controlled for many other maternal factors, and unmeasured shared familial factors by co-sibling analyses, which have not been conducted in previous studies.

Our study had some limitations. Information on spontaneous or medically indicated preterm delivery was available from 1990, which allowed exploratory analyses only in a large subcohort. More complete assessment of the underlying causes of preterm delivery would be useful in future studies to further improve risk stratification. Despite controlling for many maternal factors and shared familial exposures, residual confounding by maternal smoking, body mass index, or other factors is still possible. The study was limited to Sweden and the results might not be applicable to other countries. The study should be repeated in other diverse populations to explore for potential heterogeneity of findings in racial and ethnic subgroups. Longer follow-up to older ages will be needed in this or other large cohorts when such data become available.

\section{Comparison with other studies}

Three smaller studies that explored mortality in women who delivered preterm had conflicting results. A Finnish study of 3706 women who gave birth in 1954-63 reported that preterm delivery was associated with increased cardiovascular mortality (adjusted hazard ratio 2.06, 95\% confidence interval 1.22 to 3.47 ) but not all cause mortality $(0.96,0.67$ to 1.38) after follow-up to $1997 .{ }^{8}$ Preterm delivery was associated with modestly increased all cause mortality, however, in a Scottish study of 129920 women who gave birth in 1981-85 with follow-up to 1999 (adjusted hazard ratio $1.5,95 \%$ confidence interval 1.2 to 1.8$),{ }^{9}$ and in a Swedish study of 573437 women who gave birth in 1973-80 with follow-up to 1997 (1.23, 1.14 to 1.34). ${ }^{10}$ These studies examined all preterm deliveries combined ( $<37$ weeks) and had insufficient numbers to examine narrower pregnancy durations.

Our findings are generally consistent with previous studies that explored the birth weight of infants (which is influenced by length of pregnancy and fetal growth rate) in relation to future health risks in the mother. ${ }^{5-14}$ The largest was an Israeli study of 982091 women who gave birth in 1995-2010, which reported that those whose infants weighed less than $1500 \mathrm{~g}$ had a twofold mortality over 17 years of follow-up compared with birth weights of 3000-3500 g (adjusted hazard ratio $2.13,95 \%$ confidence interval 1.68 to 2.71$).^{5}$ 


\begin{tabular}{|c|c|c|c|c|}
\hline & Deaths & Rate* & Hazard ratio $(95 \% \mathrm{Cl}) \dagger$ & $P$ value \\
\hline \multicolumn{5}{|l|}{$0-44$ years after first delivery } \\
\hline 0 preterm & 29845 & 95.7 & Reference & - \\
\hline 1 preterm & 4000 & 130.0 & $1.27(1.23$ to 1.31$)$ & $<0.001$ \\
\hline$\geq 2$ preterm & 1074 & 161.5 & $1.61(1.51$ to 1.71$)$ & $<0.001$ \\
\hline Per additional preterm delivery & - & - & $1.24(1.21$ to 1.27$)$ & $<0.001$ \\
\hline \multicolumn{5}{|l|}{$<10$ years after first delivery } \\
\hline 0 preterm & 1883 & 15.3 & Reference & - \\
\hline 1 preterm & 286 & 24.0 & $1.38(1.22$ to 1.57$)$ & $<0.001$ \\
\hline$\geq 2$ preterm & 43 & 16.8 & $0.92(0.68$ to 1.24$)$ & 0.57 \\
\hline Per additional preterm delivery & - & - & $1.13(1.04$ to 1.24$)$ & 0.005 \\
\hline \multicolumn{5}{|l|}{ 10-19 years after first delivery } \\
\hline 0 preterm & 5227 & 56.6 & Reference & - \\
\hline 1 preterm & 746 & 81.1 & $1.31(1.21$ to 1.41$)$ & $<0.001$ \\
\hline$\geq 2$ preterm & 207 & 103.4 & $1.62(1.41$ to 1.86$)$ & $<0.001$ \\
\hline Per additional preterm delivery & - & - & $1.25(1.19$ to 1.31$)$ & $<0.001$ \\
\hline \multicolumn{5}{|l|}{ 20-44 years after first delivery } \\
\hline 0 preterm & 22735 & 235.8 & Reference & - \\
\hline 1 preterm & 2968 & 306.9 & 1.25 (1.20 to 1.30$)$ & $<0.001$ \\
\hline$\geq 2$ preterm & 824 & 395.1 & $1.65(1.54$ to 1.77$)$ & $<0.001$ \\
\hline Per additional preterm delivery & - & - & 1.24 (1.21 to 1.27$)$ & $<0.001$ \\
\hline $\begin{array}{l}\text { *Mortality rate per } 100000 \text { person } \\
\text { †Adjusted for maternal age, year of } \\
\text { mass index, smoking, pre-eclampsia } \\
\text { depression. }\end{array}$ & $\begin{array}{l}\text {, parity, ed } \\
\text { hypertensi }\end{array}$ & $\begin{array}{l}\text { on, em } \\
\text { sorders }\end{array}$ & $\begin{array}{l}\text { nt, income, region of origi } \\
\text { tes, asthma, rheumatoid a }\end{array}$ & $\begin{array}{l}\text { ody } \\
\text { ritis, and }\end{array}$ \\
\hline
\end{tabular}

This finding was consistent with those from smaller cohorts of women who gave birth in 1958 in the UK ${ }^{7}$ and in 1974-76 in Israel. ${ }^{6}$ Other studies reported increased cardiovascular ${ }^{7-13}$ and diabetes related ${ }^{14}$ mortality in women who delivered an infant with a low birth weight.

Birth weight in infants is determined by both length of pregnancy and fetal growth rate, which have different underlying processes. Our study extends previous evidence as we examined length of pregnancy more specifically in relation to long term mortality in a large population based cohort with several decades of follow-up. Our findings suggested that preterm and early term delivery were independent risk factors for increased mortality up to 40 years later. Mortality was increased after spontaneous or (even higher) medically indicated preterm delivery, and with or without preeclampsia or fetal growth restriction. These findings suggest that all women who deliver preterm, and not only subgroups with other major complications, have raised mortality risks.

We found several major causes of death associated with preterm delivery, including cardiovascular and respiratory disorders, diabetes, cancer, and other causes. These findings are similar to previously reported cause specific mortality in the offspring of preterm birth. ${ }^{202233}$ Common genetic factors have been proposed that might contribute to preterm delivery and future health outcomes. ${ }^{24} \mathrm{Co}$-sibling analyses, however, suggested that our findings were largely independent of shared genetic or early life environmental factors within families. Instead, individual specific processes involved with preterm delivery might contribute directly to subsequent development of chronic disorders and early mortality in women. The mechanisms are not established but could involve common inflammatory pathways. Increased production of proinflammatory cytokines, specifically interleukin 1 , interleukin 6 , and tumour necrosis factor, have been associated with uterine activation and the timing and start of preterm delivery. ${ }^{25-27}$ Proinflammatory pathways also play a key role in the pathogenesis of atherosclerosis and cardiovascular disease, ${ }^{28-30}$ chronic pulmonary disease, ${ }^{31}$ and specific cancers. ${ }^{32}$ Preclinical diabetes and other cardiometabolic disorders might also contribute to preterm delivery and subsequent mortality risks. Other mechanisms are also possible, including a potential role of vitamin D deficiency, which has been associated with preterm delivery ${ }^{33} 34$ and to some extent with cardiovascular, neoplastic, and metabolic disorders, although a direct cause and effect has not been established. ${ }^{35} 36$ Further experimental and clinical studies are needed to identify the relevant mechanisms, which might disclose new targets for prevention.

\section{Implications}

Premature delivery should now be recognised as a risk factor for early mortality in women. Medical records and history taking should routinely include reproductive history that covers preterm delivery and other complications of pregnancy. Women with a history of preterm delivery need long term follow-up for recommended screenings to facilitate detection and treatment of chronic disorders associated with early mortality, including cardiovascular, neoplastic, and metabolic disease. Better access to high quality preconception and prenatal care should also be a public health priority to help reduce preterm delivery. ${ }^{37}$

\section{Conclusions}

This large national cohort study suggested that preterm and early term delivery were independent risk factors for premature mortality from several major causes, and that the associated risks persist for up to 40 years later. Women who deliver prematurely need long term clinical follow-up for detection and treatment of chronic disorders associated with early mortality.

Contributors: All authors conceived and designed the study, analysed and interpreted the data, critically revised the manuscript for important intellectual content, and obtained funding. JS and KS acquired the data. CC drafted the manuscript. CC and JS did the statistical analysis. JS and KS serve as guarantors and affirm that the manuscript is an honest, accurate, and transparent account of the study being reported; that no important aspects of the study have been omitted; and that any discrepancies from the study as planned have been explained. All authors had full access to all of the data (including statistical reports and tables) in the study and take responsibility for the integrity of the data and accuracy of the data analysis. The corresponding author (CC) attests that all listed authors meet authorship criteria and that no others meeting the criteria have been omitted.

Funding: This work was supported by the National Heart, Lung, and Blood Institute at the National Institutes of Health (R01 HL139536); the Swedish Research Council; the Swedish Heart-Lung Foundation; and ALF project grant, Region Skåne/Lund University, Sweden. The funding agencies had no role in the design and conduct of the study; collection, analysis, and interpretation of the data; or the writing of the manuscript or the decision to submit it for publication.

Competing interests: All authors have completed the ICMJE uniform disclosure form at www.icmje.org/coi_disclosure.pdf and declare: support from the National Heart, Lung, and Blood Institute at the 
National Institutes of Health (R01 HL139536); the Swedish Research Council; the Swedish Heart-Lung Foundation; and ALF project grant, Region Skåne/Lund University, Sweden, for the submitted work; no financial relationships with any organisations that might have an interest in the submitted work in the previous three years; no other relationships or activities that could appear to have influenced the submitted work.

Ethical approval: The study was approved by the Regional Ethical Review Board, Lund, Sweden (No 2012/795; 2013/736).

Patient consent: Patient consent was not required as the study used only de-identified registry based secondary data.

Data sharing: No additional data available.

The corresponding author (CC) affirms that the manuscript is an honest, accurate, and transparent account of the study being reported, no important aspects of the study have been omitted, and any discrepancies from the study as planned have been explained.

Dissemination to participants and related patient and public communities: The results will be disseminated to patients and the public through a website and press releases suitable for a nonspecialised audience.

This is an Open Access article distributed in accordance with the Creative Commons Attribution Non Commercial (CC BY-NC 4.0) license, which permits others to distribute, remix, adapt, build upon this work non-commercially, and license their derivative works on different terms, provided the original work is properly cited and the use is noncommercial. See: http://creativecommons.org/licenses/by-nc/4.0/.

1 Chawanpaiboon S, Vogel JP, Moller AB, et al. Global, regional, and national estimates of levels of preterm birth in 2014: a systematic review and modelling analysis. Lancet Glob Health 2019;7:e37-46. doi:10.1016/S2214-109X(18)30451-0

2 Tanz LJ, Stuart JJ, Williams PL, et al. Preterm delivery and maternal cardiovascular disease risk factors: The Nurses' Health Study II. J Womens Health (Larchmt) 2019;28:677-85. doi:10.1089/ jwh.2018.7150

3 Wu P Gulati M, Kwok CS, et al. Preterm delivery and future risk of maternal cardiovascular disease: a systematic review and meta-analysis. J Am Heart Assoc 2018;7:e007809. doi:10.1161/ JAHA.117.007809

4 Crump C, Sundquist J, Howell EA, McLaughlin MA, Stroustrup A, Sundquist K. Pre-term delivery and risk of ischemic heart disease in women. J Am Coll Cardiol 2020;76:57-67. doi:10.1016/j. jacc.2020.04.072

5 Grisaru-Granovsky S, Gordon ES, Haklai Z, et al. Delivery of a very low birth weight infant and increased maternal risk of cancer and death: a population study with 16 years of follow-up. Cancer Causes Control 2015;26:1593-601. doi:10.1007/s10552-015-0653-X

6 Friedlander Y, Manor O, Paltiel O, et al. Birth weight of offspring, maternal pre-pregnancy characteristics, and mortality of mothers: the Jerusalem perinatal study cohort. Ann Epidemiol 2009;19:112-7. doi:10.1016/j.annepidem.2008.11.002

7 Davey Smith G, Hyppönen E, Power C, Lawlor DA. Offspring birth weight and parental mortality: prospective observational study and meta-analysis. Am J Epidemiol 2007;166:160-9. doi:10.1093/aje/ kwm054

8 Smith GD, Whitley E, Gissler M, Hemminki E. Birth dimensions of offspring, premature birth, and the mortality of mothers. Lancet 2000;356:2066-7. doi:10.1016/S0140-6736(00)03406-1

9 Smith GC, Pell IP, Walsh D. Pregnancy complications and materna risk of ischaemic heart disease: a retrospective cohort study of 129,290 births. Lancet 2001;357:2002-6. doi:10.1016/S01406736(00)05112-6

10 Smith GD, Sterne J, Tynelius P, Lawlor DA, Rasmussen F. Birth weight of offspring and subsequent cardiovascular mortality of the parents. Epidemiology 2005;16:563-9. doi:10.1097/01. ede.0000164790.96316.c0

11 Davey Smith G, Hart C, Ferrell C, et al. Birth weight of offspring and mortality in the Renfrew and Paisley study: prospective observational study. BMJ 1997:315:1189-93. doi:10.1136/bmj.315.7117.1189

12 Smith GD, Harding S, Rosato M. Relation between infants' birth weight and mothers' mortality: prospective observational study. BMJ 2000;320:839-40. doi:10.1136/bmj.320.7238.839

13 Li CY, Chen HF, Sung FC, et al. Offspring birth weight and parental cardiovascular mortality. Int J Epidemiol 2010;39:1082-90. doi:10.1093/ije/dyq045
14 Li CY, Sung FC, Hsieh PC, Lee MD, Lu TH, Chen HF. Offspring birth weight and risk of mortality from diabetes in mothers. J Epidemiol Community Health 2011;65:775-9. doi:10.1136/ jech.2009.100644

15 Statistics Sweden. The Swedish Medical Birth Register [Available from: https://www.socialstyrelsen.se/en/statistics-and-data/ registers/register-information/the-swedish-medical-birth-register/ accessed October 1, 2019].

16 Stock S, Norman J. Preterm and term labour in multiple pregnancies. Semin Fetal Neonatal Med 2010;15:336-41. doi:10.1016/j. siny.2010.06.006

17 Sterne JA, White IR, Carlin JB, et al. Multiple imputation for missing data in epidemiological and clinical research: potential and pitfalls. BMJ 2009;338:b2393. doi:10.1136/bmj.b2393

18 Cummings P. Missing data and multiple imputation. JAMA Pediatr 2013:167:656-61. doi:10.1001/jamapediatrics.2013.1329

19 Grambsch PM. Goodness-of-fit and diagnostics for proportional hazards regression models. Cancer Treat Res 1995;75:95-112. doi:10.1007/978-1-4615-2009-2 5

20 Crump C, Sundquist J, Winkleby MA, Sundquist K. Gestational age at birth and mortality from infancy into mid-adulthood: a national cohort study. Lancet Child Adolesc Health 2019;3:408-17. doi:10.1016/S2352-4642(19)30108-7

21 VanderWeele TJ. Causal interactions in the proportional hazards model. Epidemiology 2011;22:713-7. doi:10.1097/ EDE Ob013e31821db503

22 Crump C, Sundquist K, Sundquist J, Winkleby MA. Gestational age at birth and mortality in young adulthood. JAMA 2011;306:1233-40. doi:10.1001/jama.2011.1331

23 Crump C, Sundquist K, Winkleby MA, Sundquist J. Early-term birth (37-38 weeks) and mortality in young adulthood. Epidemiology 2013;24:270-6. doi:10.1097/EDE.0b013e318280da0f

24 DeFranco E, Teramo K, Muglia L. Genetic influences on preterm birth. Semin Reprod Med 2007;25:40-51. doi:10.1055/s-2006-956774

25 Thomson AJ, Telfer JF, Young A, et al. Leukocytes infiltrate the myometrium during human parturition: further evidence that labour is an inflammatory process. Hum Reprod 1999;14:229-36. doi:10.1093/humrep/14.1.229

26 Challis JR, Lockwood CJ, Myatt L, Norman JE, Strauss JF3rd, Petraglia F. Inflammation and pregnancy. Reprod Sci 2009;16:206-15. doi:10.1177/1933719108329095

27 Cappelletti M, Della Bella S, Ferrazzi E, Mavilio D, Divanovic S Inflammation and preterm birth. / Leukoc Biol 2016:99:67-78. doi:10.1189/jlb.3MR0615-272RR

28 Blake GJ, Ridker PM. Novel clinical markers of vascular wall inflammation. Circ Res 2001;89:763-71. doi:10.1161/hh2101.099270

29 Libby P. Inflammation and cardiovascular disease mechanisms. Am Clin Nutr 2006;83:456S-60S. doi:10.1093/ajcn/83.2.456S

30 Libby P, Ridker PM, Hansson GK, Leducq Transatlantic Network on Atherothrombosis. Inflammation in atherosclerosis: from pathophysiology to practice. J Am Coll Cardiol 2009;54:2129-38. doi:10.1016/j.jacc.2009.09.009

31 Barnes PJ. Inflammatory mechanisms in patients with chronic obstructive pulmonary disease. J Allergy Clin Immunol 2016;138:16 27. doi:10.1016/j.jaci.2016.05.011

32 Mantovani A. Molecular pathways linking inflammation and cancer. Curr Mol Med 2010;10:369-73 doi:10.2174/156652410791316968

33 Zhou SS, Tao YH, Huang K, Zhu BB, Tao FB. Vitamin D and risk of preterm birth: Up-to-date meta-analysis of randomized controlled trials and observational studies. J Obstet Gynaecol Res 2017:43:24756. doi:10.1111/jog.13239

34 Wagner CL, Baggerly C, McDonnell SL, et al. Post-hoc comparison of vitamin $\mathrm{D}$ status at three timepoints during pregnancy demonstrates lower risk of preterm birth with higher vitamin D closer to delivery. J Steroid Biochem Mol Biol 2015;148:256-60. doi:10.1016/j. isbmb.2014.11.013

35 Rosen CI, Adams IS, Bikle DD, et al. The nonskeletal effects of vitamin D: an Endocrine Society scientific statement. Endocr Rev 2012;33:456-92. doi:10.1210/er.2012-1000

36 Bouillon R, Marcocci C, Carmeliet G, et al. Skeletal and extraskeletal actions of vitamin D: current evidence and outstanding questions. Endocr Rev 2019;40:1109-51. doi:10.1210/er.2018-00126

37 Shapiro-Mendoza CK, Barfield WD, Henderson Z, et al. CDC Grand Rounds: public health strategies to prevent preterm birth. MMWR Morb Mortal Wkly Rep 2016;65:826-30. doi:10.15585/mmwr. $\mathrm{mm} 6532 \mathrm{a} 4$

Web appendix: Supplementary material 